\title{
THE PATTERN OF INDUCTION OF APOPTOSIS DURING INFECTION WITH MHV-3 CORRELATES WITH STRAIN VARIATION IN RESISTANCE AND SUSCEPTIBILITY TO LETHAL HEPATITIS
}

\author{
Michail Belyavskyi, 'Gary A. Levy, ${ }^{2}$ and Julian L. Leibowitz ${ }^{1}$ \\ 'Department of Pathology and Laboratory Medicine \\ Texas A\&M University College of Medicine \\ 208 Reynolds Building \\ College Station, Texas 77843-1114 \\ ${ }^{2}$ Multi Organ Transplant Program \\ The Toronto Hospital-University of Toronto \\ 621 University Ave. \\ NU-10-151, Toronto, Ontario
}

\section{ABSTRACT}

In the present study we have investigated the possibility that strain specific differences in the induction of apoptosis in macrophages could play a role in the resistance of strain $\mathrm{A} / \mathrm{J}$ mice to MHV-3 induced hepatitis. MHV-3 infected macrophages from Balb/c and $\mathrm{A} / \mathrm{J}$ mice were analyzed at various time points after infection. Apoptosis in $\mathrm{A} / \mathrm{J}$ macrophages could be detected at $8 \mathrm{~h}$ post infection and increased significantly by $12 \mathrm{~h}$, when almost $50-70 \%$ of the infected cells were undergoing apoptosis. In Balb/c macrophages, apoptotic changes were less pronounced and were observed in only $5-10 \%$ of the cells. MHV-3 induced apoptosis was inversely correlated with the ability of this virus to induce expression of fgl-2 prothrombinase protein and syncytia formation. Infected macrophages from $\mathrm{A} / \mathrm{J}$ mice did not express fgl-2 protein and did not form syncytia. In contrast, infection of Balb/c derived macrophages resulted in fgl-2 expression and extensive syncytia formation. These data fit a model in which apoptosis of virally infected cells is a protective response which eliminates cells whose survival might be harmful for the whole organism.

Coronaviruses and Arteriviruses, edited by Enjuanes et al. 


\section{INTRODUCTION}

Host protective non-specific responses are important factors in the pathogenesis of viral infections. Macrophages can limit viral infections by phagocytosing and killing virus particles, as well as by elaborating interferons and pro-inflammatory cytokines which can limit virus replication. The ability of viruses to replicate efficiently in macrophages is an important determinant in the pathogenesis of many diseases, including the hepatitis induced in mice during infection with mouse hepatitis virus (MHV) (Piazza, 1969). In fully susceptible strains of mice (Balb/c), MHV-3 infection produced a fulminant hepatitis, characterized by abnormalities of the hepatic microcirculation (Levy, et al., 1983). Strain A mice (A/J) are resistant to the development of disease even though MHV-3 replicates in their livers (Dindzans et al., 1985). The induction of a unique macrophage prothrombinase (PCA) in response to MHV-3 infection correlated with the severity of infection. This unregulated elaboration of PCA during infection is a major contributor to the pathogenesis of the lethal hepatitis in susceptible strains of mice (Dindzans et al., 1986). Apoptosis can be viewed as a protective mechanism to eliminate infected cells, whose survival might be harmful for the organism. Apoptosis is characterized by distinctive morphological and biochemical changes including nucleolytic degradation of chromosomal DNA, compaction and fragmentation of chromatin, cellular shrinkage, cytoplasmic blebbing, and fragmentation.

In the present work we have examined a possible role of apoptosis in the differences in response to MHV-3 infection. Macrophages derived from strain $\mathrm{A} / \mathrm{J}$ mice undergo rapid apoptosis after infection with MHV-3, whereas macrophages from Balb/c mice do not. We propose that the rapid induction of apoptosis in macrophages from resistant mice is a key protective non-specific host response to MHV-3 infection. It prevents what would otherwise be an injurious prothrombinase response and eliminates infected macrophages which might be harmful for the whole organism.

\section{MATERIALS AND METHODS}

\subsection{Virus and Cells}

Stocks of MHV-3 were grown as described by Levy et al (1981). Thioglycollate elicited peritoneal macrophages were prepared from mice and infected as described (Parr et al., 1995). At various times post infection (p.i.) cells were harvested with a rubber policeman, resuspended in PBS containing $2 \%$ paraformaldehyde, incubated at $4^{\circ} \mathrm{C}$ for $10 \mathrm{~min}$ utes, washed and fixed in ice cold $70 \%$ ethanol. The samples were stored at $-20^{\circ} \mathrm{C}$ before analysis by flow cytometry.

\subsection{BrdUrd Labeling}

Macrophages were infected with MHV-3 and labeled in media containing $10 \mu \mathrm{M}$ BrdUrd (Belyavskyi, 1994). At the indicated time points macrophages were harvested with a rubber policeman, washed twice in PBS, fixed in $70 \%$ ethanol, and kept at $-20^{\circ} \mathrm{C}$ until analyzed.

\subsection{Flow Cytometry}

Fluorescence measurements were performed on a Becton Dickinson FACS flow cytometer as described previously (Belyavskyi, 1994). Before analysis cells were passed 
through a 23-gauge needle to break up clusters of cells. Fixed macrophages were washed twice in PBS (pH 7.0) and resuspended in $0.5 \mathrm{ml}$ of propidium iodide (PI) solution for 20 minutes at $37^{\circ} \mathrm{C}$. The data were gated to eliminate particles not the correct size for intact cells, and a two-parameter histogram of light scatter versus red fluorescence was plotted. At least $5 \times 10^{4}$ cells were counted in each assay. Relative anti-BrdUrd fluorescence intensity (RFI) was calculated as described (Schutte et al., 1987).

\subsection{TUNEL Assay}

TUNEL assays were performed on cells grown on chamber slides using a kit purchased from Promega Corp. TUNEL-positive cells were visualized by fluorescence microscopy.

\subsection{Western Blotting}

Cytoplasmic extracts were prepared from $\mathrm{A} / \mathrm{J}$ and Balb/c macrophages with $0.5 \%$ NP-40. Proteins $(20 \mu \mathrm{g})$ were resolved by SDS-PAGE, transferred to Immobilon membranes, and probed with antibodies to the fgl- 2 or the MHV N proteins and detected by ECL (Amersham).

\section{RESULTS}

\subsection{MHV-3 Induced Apoptosis}

The majority of Balb/c macrophages infected with MHV-3 developed pronounced cytopathic effects, namely cell fusion with syncytial giant cell formation, after which the cells die. In $\mathrm{A} / \mathrm{J}$ macrophages there was no detectable syncytia formation up to 8-12 hpi.

To examine the relationship between macrophages which were dying by apoptosis after MHV-3 infection and those that were incorporated into or form syncytia, we used the in situ TUNEL assay. A/J and Balb/c macrophages were mock or MHV-3 infected and TUNEL staining was performed $12 \mathrm{hpi}$ and visualized by fluorescence microscopy.

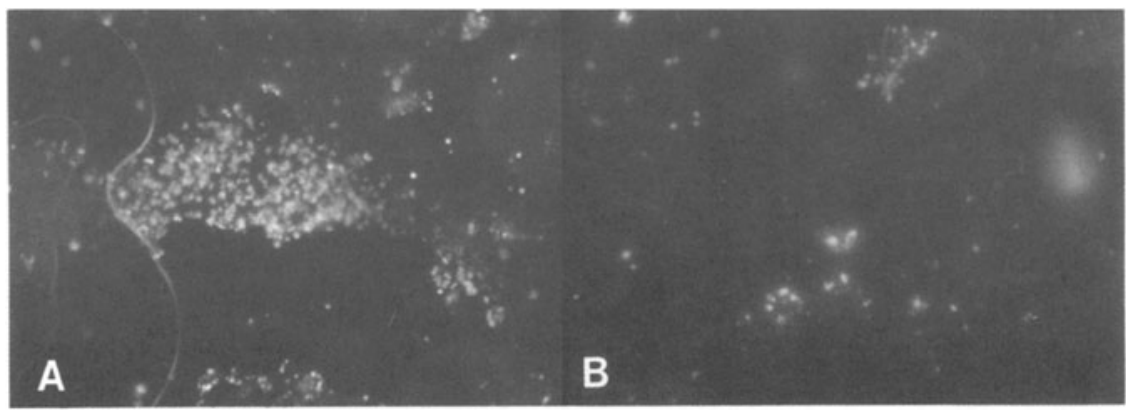

Figure 1. Detection of apoptosis by TUNEL assay. Macrophages from $\mathrm{A} / \mathrm{J}$ and Balb/c mice were infected with MHV-3 and processed for TUNEL assay at $8 \mathrm{hpi}$. Representative fluorescence photomicrographs are shown for $\mathrm{A} / \mathrm{J}(\mathrm{A})$ and Balb/c (B) macrophages. 
Mock-infected A/J or Balb/c derived cells had the typical morphology of intact macrophages and contained few TUNEL-positive apoptotic cells (not shown). The majority of MHV-infected Balb/c macrophages underwent cell fusion forming large syncytia. TUNEL positive cells were observed only in a small fraction of the macrophages (about $10 \%$ ), and these cells were not incorporated into syncytia. Quite different results were observed when $\mathrm{A} / \mathrm{J}$ macrophages were infected with MHV-3. There was no visible syncytia formation during the first $12 \mathrm{~h}$ after infection. Cell counts indicated that the number of TUNEL-positive cells made up $60-70 \%$ of the population. Based on these data we conclude that TUNEL-positive macrophages were not incorporated into or form syncytia during MHV-3 infection.

To further address the possibility that only single cells which were not incorporated into syncytia underwent apoptosis we used flow cytometric analysis. Sample preparation and gating paremeters for the flow cytometer exclude syncytial giant cells from the analysis. Thus macrophages were infected with MHV-3 and at various times after infection analyzed for DNA content by flow cytometry. At 4 hpi the majority of infected $\mathrm{A} / \mathrm{J}$ and Balb/c macrophages show a typical G0+G1 DNA profile, similar to that of uninfected cells (not shown). Between 6-8 hpi a subpopulation of cells with less than G0+G1 DNA content appeared (about 20\%), which subsequently increased (up to 50\%) between 8-12 hpi (data not shown). The timing of this change in DNA profile was closely correlated with an increase in the proportion of shrunken cells detected by $90^{\circ}$ light scatter (data not shown). DNA fragmentation with a resultant decrease in cellular DNA content and decreasing cell size are the hallmarks of apoptosis (Wyllie et al., 1980).

\subsection{Fgl-2 Expression}

We have previously shown that the appearence of fgl-2 mRNA after MHV-3 infection is delayed by about $2 \mathrm{~h}$ in $\mathrm{A} / \mathrm{J}$ macrophages $(5-6 \mathrm{hpi})$ relative to its appearence in Balb/c macrophages (3-4 hpi). To determine if fgl-2 protein was synthesized in MHV-3 infected $\mathrm{A} / \mathrm{J}$ macrophages, cell lysates were prepared at various times after infection and analyzed by western blotting (Fig. 2A). Fgl-2 protein was not detected in $\mathrm{A} / \mathrm{J}$ macrophages at any time examined, while in Balb/c macrophages fgl-2 protein was detected at $8 \mathrm{hpi}$ and increased by $12 \mathrm{hpi}$. To verify that differences in fgl-2 protein expression were not related to variation in infectivity between $\mathrm{A} / \mathrm{J}$ and $\mathrm{Balb} / \mathrm{c}$ macrophages the same samples were probed with anti-MHV nucleocapsid antibodies (Fig. 2B). The nucleocapsid protein was detected in both $\mathrm{A} / \mathrm{J}$ and $\mathrm{Balb} / \mathrm{c}$ macrophages.

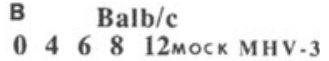

A

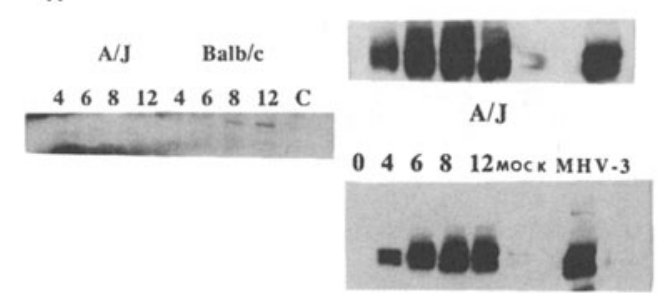

Figure 2. Western blot analysis of fgl-2 and nucleocapsid proteins. $\mathrm{A} / \mathrm{J}$ and $\mathrm{Balb} / \mathrm{c}$ macrophages were infected with MHV-3 and at the indicated times, cytoplasmic extracts were prepared and analyzed by immunoblotting with antibodies recognizing fgl-2 (A) and MHV nucleocapsid (B). 


\subsection{BrdUrd Incorporation into Macrophages after MHV-3 Infection}

A comparison of DNA histograms from uninfected and MHV-3 infected $\mathrm{A} / \mathrm{J}$ and Balb/c macrophages revealed that starting at 2-4 hpi a small fraction (5-15\%) of cells contained typical S phase DNA content (data not shown). In uninfected macrophages the number of cells with $S$ phase DNA content was $1-2 \%$. To confirm this observation we directly measured the initiation of DNA replication by BrdUrd labeling infected and uninfected macrophages. At various times after infection the amount of incorporated BrdUrd was measured by flow cytometry (Fig. 3). Over the first $4 \mathrm{~h}$ of MHV-3 infection of A/J macrophages there was no detectable BrdUrd labeling above the background level. Between 4-6 hpi the amount of BrdUrd labeling started to increase, and then dropped back to the background level after $8 \mathrm{hpi}$. The pattern of BrdUrd labeling of infected Balb/c macrophages was similar. Labeling began between 2-4 hpi and then decreased, reaching background levels at $8 \mathrm{hpi}$. During the course of these experiments the infected cells were constantly incubated in media containing BrdUrd. If the proportion of the cells in which DNA replication was stimulated by MHV-3 remained fairly constant at various times after infection, and/or those infected cells proceeded normally to the next stage of the cell cycle, then the amount of incorporated BrdUrd would be proportional to the post infection incubation time. The data indicate that after a transient increase, the amount of BrdUrd incorporated into infected macrophages decreases with increasing hpi. One possible explanation of these results is that cells incorporating BrdUrd were being eliminated from the culture. A possible mechanism for this process is the induction of apoptosis in the cells with "unscheduled" DNA replication.

\section{DISCUSSION}

In the present study the basic mechanisms underlying the difference in response in fully susceptible and resistant strains of mice to MHV-3 infection were examined. To our

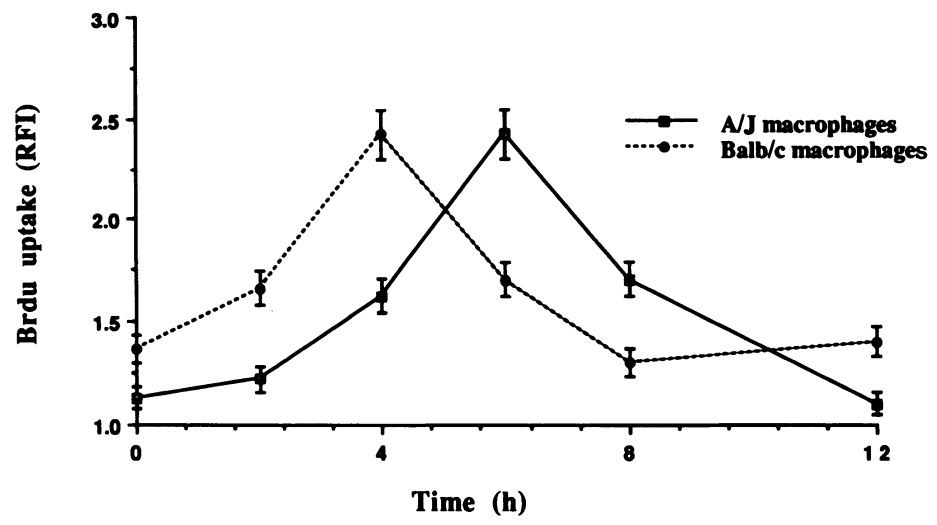

Figure 3. BrdUrd uptake in $\mathrm{A} / \mathrm{J}$ and Balb/c macrophages infected with MHV-3. Macrophages were infected with MHV-3, labeled with BrdUrd, and analyzed by flow cytometry. Each data point is the mean value of three independent experiments. The error bars indicate the standard errors of the mean. 
knowledge this study is the first demonstration of MHV-3 induced apoptosis, and raises the possibility that this is a key protective non-specific host response to the infection.

Our data, using two different methods to detect apoptosis, reveals that only single cells not incorporated into syncytia underwent apoptosis. This was true in both $\mathrm{Balb} / \mathrm{c}$ and $\mathrm{A} / \mathrm{J}$ macrophages, although apoptosis was much greater for the $\mathrm{A} / \mathrm{J}$ derived cells. The mechanism by which MHV-3 induces apoptosis in macrophages is unknown. Our flow cytometric analysis of BrdUrd incorporation into $\mathrm{A} / \mathrm{J}$ and Balb/c macrophages after MHV-3 infection demonstrated a temporary increase in BrdUrd labeling between $4-6 \mathrm{hpi}$. The amount of BrdUrd incorporated into cellular DNA subsequently dropped down to the background level, though the cells were continuously incubated in media with BrdUrd. Terminally differentiated cells, including macrophages, do not normally incorporate BrdUrd unless they are stimulated to initiate DNA synthesis. Cells which incorporated BrdUrd after MHV-3 infection should have been present in the infected cultures, unless they were specifically and constantly eliminated. This suggests that like several DNA viruses, infection of macrophages with MHV-3 overcomes the multiple host cell checkpoints that detect and prevent uncontrolled initiation of DNA synthesis. This observation provides an indication that the same pathways to apoptosis which are triggered by some DNA viruses (Cuff and Ruby, 1996) might also be involved in the induction of apoptosis by MHV-3. The difference in the outcome of MHV-3 infection of macrophages amongst the two strains could be due to the somewhat more rapid replication of MHV-3 in Balb/c macrophages than in A/J macrophages (Macnaughton and Patterson, 1980). This could commit infected Balb/c macrophages to high levels of S protein expression, with resulting cell fusion, prior to the cells acting on the apoptotic signal. In this scenario, in Balb/c mice MHV-3 simply outruns the apoptotic response, in $\mathrm{A} / \mathrm{J}$ mice the response is effective. Other possible explanations of the strain-related differences in the ability of MHV-3 to induce apoptosis include variations in bcl-2 levels or other proteins important in decreasing programmed cell death.

Macrophages from A/J mice do not elaborate fgl-2 protein synthesis in response to MHV-3 infection, although there is a slow (compared to that seen in Balb/c macrophages) induction of prothrombinase mRNA. This suggests the possibility that in $\mathrm{A} / \mathrm{J}$ macrophages, the rapid development of apoptosis or the signals leading to apoptosis during MHV-3 infection could supervene and inhibit fgl-2 protein synthesis before it is well established, thus contributing to the resistance of this strain of mice to MHV-3 induced hepatitis.

\section{ACKNOWLEDGMENTS}

This work was supported by NIH grant AI31069 and Canadian MRC program project grant PPG11810. We thank Drs. Helmut Sauer and Van Wilson for critical comments on this manuscript.

\section{REFERENCES}

Belyavskyi, M., Miller, J., and Wilson, V., 1994, The bovine papillomavirus E1 protein alters the host cell cycle and growth properties, Virology 204:132-143.

Cuff, S., and Ruby, J., 1996, Evasion of apoptosis by DNA viruses, Immun.Cell Biol. 74: 527-537.

Dindzans, V., MacPhee, P., Fung, L., Leibowitz, J., and Levy, G., 1985, The immune response to mouse hepatitis virus: expression of monocyte procoagulant activity and plasminogen activator during infection in vivo, $J$. Immunol. 135:4189-4197. 
Dindzans, V., Skamene, E., and Levy, G., 1986, Susceptibility/resistance to mouse hepatitis virus strain 3 and macrophage procoagulant activity are genetically linked and controlled by two non- $\mathrm{H} 2$-linked genes, $\mathrm{J} . \mathrm{Im}$ munol. 137:2355-2360.

Levy, G. A., J. L. Leibowitz, and T. S. Edgington., 1981, The induction of monocyte procoagulant activity by murine hepatitis virus MHV-3 parallels disease susceptibility in mice, J. Exp. Med. 154:1150-1163.

Levy, G., MacPhee, P., Fung, L., Fisher, M., and Rappaport, A., 1983, The effect of mouse hepatitis virus infection on microcirculation of the liver, Hepatology 3: 964-973.

Macnaughton, M., and Patterson, S., 1980, Mouse hepatitis virus strain 3 infection of C57, A/Sn and A/J strain mice and their macrophages, Arch. Virol. 66:71-75.

Parr, R. L., Fung, L. S., Reneker, S. J., Myers-Mason, N., Leibowitz, J. L., and Levy, G. A., 1995, Association of mouse fibrinogen like protein (musfiblp) with murine hepatitis virus induced prothrombinase activity, $J$. Virol. 69:5033-5038.

Piazza, M., 1969, “Experimental viral hepatitis”. CA Thomas, Springfield, IL.

Schutte, B., Reynders, M., van Assche, C. L. M., Hupperets, P. S. G. J., Bosman, F. T., and Blijham, G. H., 1987, An improved method for the immunocytochemical detection of bromodeoxyuridine labeled nuclei using flow cytometry, Cytometry 8:372-376.

Wyllie, A. H., Kerr, J. F. R., and Currie, A. R., 1980, Cell death: The significance of apoptosis, Int. Rev. Cytology 68:251-306 